\title{
Language Mixings in Heritage Language Education: A Systematic Review
}

\author{
Yizhe Jiang \\ The Ohio State University, US \\ jiang.1878@osu.edu
}

DOI: http://doi.org/ 10.36892/ijlls.v3i2.614

$\begin{array}{ll}\text { Received: } & \text { Abstract } \\ \text { 30/04/2021 } & \text { The overarching research question for this paper is what work has been done } \\ \text { on heritage languages worldwide through a language mixing lens. Given the } \\ \text { Accepted: } & \text { increasing research interest in this topic and the scarcity of previous } \\ \text { 15/06/2021 } & \text { secondary studies, a systematic review was conducted on the empirical data at } \\ & \text { the intersection of language mixing and heritage language education, in and } \\ \text { Keywords: } & \text { out of schools. Thematic analysis and frequency analysis were carried out on } \\ \text { systematic review, } & \text { qualified empirical sources gathered from Scopus, Web of Science, and } \\ \text { language mixing, } & \text { Linguistics and Language Behavior Abstracts (LLBA). After sharing } \\ \text { translanguaging, } & \text { backgrounds on heritage language education and language mixing with } \\ \text { heritage language } & \text { relative terms and perspectives, the paper presents findings from the review } \\ \text { education, research } & \text { based on } 23 \text { peer-reviewed empirical journal articles, focusing specifically on } \\ \text { trends } & \text { three aspects: (a) the main theoretical approaches and definitions employed } \\ & \text { for language mixing; (b) the characterization of language mixing for } \\ & \text { instruction and its impacts on heritage language education; (c) the parent and } \\ & \text { community language mixing activities for children's heritage language } \\ & \text { learning. The limitations of the existing studies and the implications for } \\ & \text { educators and researchers are later discussed. It is hoped that this article will } \\ & \text { further our knowledge on this topic and provide pointed implications for } \\ \text { future education and research. }\end{array}$

\section{INTRODUCTION}

Heritage language, also known as "mother tongue", "native language", "home language", "community language", and "first language", is a relatively new area in language education for minorities which has blossomed from Fishman's work in 1964. From a sociocultural perspective, heritage language plays an important role in the learners' identity construction (He, 2010; Leeman, 2005). Scholars have also found that the improvement of heritage language competence can cement the speakers' bonds with family and co-ethnic groups, and finally leads to the betterment of our society (Cho, 2000). Hence, heritage language learning programs, formal and informal, are on the rise aiming to facilitate the wellbeing of the minority language speakers and encourage linguistic and cultural diversity around the globe. In the past few decades, we have witnessed a growing body of studies on heritage language acquisition in educational settings (e.g., Beaudrie, 2011; Kondo-Brown, 2003). Not like elite and elective bilinguals with limited authentic resources of second or foreign languages beyond the classroom, heritage language speakers generally pick up their mother tongues in the family and community without formal instruction. Thus, family and community involvement in heritage language acquisition is also worthy of investigation. It is approved that heritage learners' language competence is affected by parental attitudes (Tse, 2001), birth order (Li, 2008), community supports (Oriyama, 2010), and so forth. 
As language mixing has gained currency in recent years, there has been an increasing interest in the roles of language mixing in heritage language acquisition. Many researchers claim that language mixing efforts are beneficial to students' higher-order thinking (Stewart \& Hansen-Thomas, 2016), literacy development (Machado \& Hartman, 2009), as well as social integration (Gutiérrez, Baquedano-López, \& Tejeda, 1999). To capture the research trends and generate implications for future research and practices, a systematic review was conducted on 23 empirical research journal articles focusing on language mixing efforts for heritage language learning in and out of instructional settings.

\section{REVIEW OF LITERATURE}

\subsection{Heritage Language Education}

Valdés defines heritage languages as "nonsocietal and nonmajority languages spoken by groups often known as linguistic minorities" (2005, p. 411). Based on this definition, heritage language students refer to "those members of linguistic minorities who are concerned about the study, maintenance, and revitalization of their minority languages" (Valdés, 2005, p. 411). According to Fishman (2001), in the American context, heritage language maintenance refers to the preservation and revitalization of an indigenous (e.g., Zuni, Cherokee), an immigrant (e.g., Indonesian, Korean), or a colonial language (e.g., German, French). This paper expands the scope of Fishman's classification of heritage languages from the State to the globe and seeks to investigate what work has been done on heritage languages worldwide, either popular or endangered, through a language mixing lens.

Due to the caretakers' mixed perceptions toward the minority languages and various expectations on their children's future careers, researchers have documented different language policies in the home milieu. An oft-cited scholar in this area is Guofang Li who has conducted a multi-case study on Chinese-Canadian children's home language environments (2006). In this study ( $\mathrm{Li}, 2006$ ), a father embraces his daughter's potential in both English and Mandarin, encouraging her to flexibly mix the two languages, whereas a mother shows a negative attitude towards the mixture of English and Cantonese and only speaks in English with her son. In addition, parents usually draw on multiple linguistic and cultural resources to boost the learners' motivation including songs, books, and movies, to name only a few. However, in the past, most of the studies on family language rules were aimed at students' bilingualism or dominant language capacities to facilitate their engagement into the mainstream culture without clear emphasis on their heritage language maintenance. It is until recently that remarkable attention has been paid to parental involvement in heritage language maintenance.

Beyond families, many communities provide stages in various forms for minority children to learn their heritage languages and cultures, such as the celebrations of Chinese Spring Festival and Italian American Museum in New York City. In the past few years, aware of the erosion of the heritage languages impacted by powerful lingua francas, many minority communities have set up weekend complementary schools providing heritage language instructions. Moreover, some daily schools offer bilingual or heritage language programs for indigenous and immigrant children. The differences in learning processes and resources between second/foreign language learners and heritage language learners beckon us to be attentive to the theories adopted by heritage language researchers and educators. Language mixing, which has garnered our increasing attention recently, has been more and more widely applied to heritage language education. In the following section, the theories of language mixing with multiple perspectives and the discussions on language mixing in and out of school are provided. 


\subsection{Language Mixings in Households, Communities, and Classrooms}

Various terms have been used for the language mixing ideologies and practices. At first, language was generally viewed as "bound systems and fixed codes" (Gort\&Sembiante, 2015 ) resonating with traditional perspectives of second language acquisition. Guided by this view towards language, code-switching has usually been viewed as "the kind of discourse in which words originating in two different language systems are used side-by-side" (Backus, 2005 , p. 307). Within the last few years, the perceptions of many researchers toward the nature of language have been changed from fixed to fluid, underpinning many emerging terms such as flexible bilingualism, hybrid language use, translingual, and translanguaging which is the most noteworthy among them. "Flexible bilingualism" defined by Blackledge \& Creese focuses on individual agency instead of separate, discrete and bounded languages (2010). According to Gutiérrez, Baquedano-López, and Alvarez (2001), "Hybrid language use is more than simple code-switching as the alternation between two codes. It is more a systematic, strategic, affiliative and sense-making process" (p. 128). With permeable language boundaries, translanguaging is defined as:

a process by which students and teachers engage in complex discursive practices that include ALL the language practices of ALL students in a class in order to develop new language practices and sustain old ones, communicate and appropriate knowledge, and give voice to new sociopolitical realities by interrogating linguistic inequality (García \& Kano, 2014, p. 261)

Considering multilingual composing, Canagarajah (2011) explains that translingual research with a product-oriented perspective is more encouraged since the translangauging process is too complicated and subtle to capture. The application of this perspective into composing instruction is often accompanied by multimodalities. For example, Childs invited the students and teachers to discuss humanizing pedagogy using photos and poems with flexible language choices (2016).

In the bilingual home milieu, the linguistic features of language mixing are reported by scholars to a great extent. For instance, $\mathrm{Ng}$ and $\mathrm{He}$ (2004) studied the structural form of code-switching between English and Chinese based on a 30,000-word corpus of conversations in four tri-generational Chinese families in New Zealand and have found that between-turns code-switching happened more frequently than within-turns code-switching. This is in alignment with the prevalent linguistic analyses of language mixing in bilingual speech such as the investigation of Quebec French code-switchers' usage of phrase-final prepositions by Poplack, Zentz, and Dion (2012). A lesser-known aspect of language mixing, however, is how it influences language acquisition especially for the heritage languages.

Studies on how communities integrate and leverage local semiotic repertoires are few when compared to those conducted with household language mixings. What is more, communities are tightly associated with families and schools in language mixing research. For example, Kim, Dorner, and Song (2021) in the U.S. investigated a community language mixing project for students at a Spanish immersion elementary school and their families to make storybooks. In this work, they put forward a concept "community translanguaging" as meaning-making process and product of the collaboration among children, family, and community, leveraging their linguistic and cultural resources. From the study, the researchers claim that the community translanguaging practices promote students' multiliteracy development through the concerted efforts of family, community, and school. Likewise, studies on community language mixing efforts are rarely aimed at heritage language education. Therefore, the author took a closer look at primary studies on heritage language learning in family and community through a language mixing lens in this systematic review.

Many scholars discuss the affordances of language mixing as pedagogy. Creese and Blackledge (2010) point out that such pedagogy is aimed at sustaining minority students' dynamic language through meaningful learning. Sayer (2008) shows that beyond the 
boundary between English and Spanish, language mixing in pedagogy makes contributions to Latino students' construction of confident ethnolinguistic identity. With the term "translanguaging as pedagogy", García and Li (2014) suggest that language mixing pedagogy encourages students to investigate social justice and question the social hierarchies with a sociocritical approach.

According to Cenoz and Gorter (2017), there are two types of language mixing efforts in pedagogy: pedagogical translanguaging and spontaneous translanguaging. On the one hand, "pedagogical translangauging" is "planned by the teacher inside the classroom and can refer to the use of different languages for input and output or to other planned strategies based on the use of students' resources from the whole linguistic repertoire" (p. 194). On the other hand, spontaneous translanguaging, the unplanned language mixing practice, also plays an important role in heritage language classrooms (Cenoz \& Gorter, 2017). In the finding section of this paper, the language mixing pedagogy documented by the selected studies is arranged within these two categories.

\subsection{Former Reviews and the Current Study}

To the best knowledge of the author, in spite of the relatively rich research carried on pedagogical translanguaging in academic content subjects like science, math, and social studies, the effects of this kind of pedagogy in heritage language classes remain seldomexplored, let alone the systematic review on this topic. Furthermore, there is no systematic review on community and parent involvement in children's heritage language maintenance through a language mixing lens. To address the research gaps, this article presents a systematic review conducted in 2020 covering empirical peer-reviewed journal articles of studies on heritage language education based on a language mixing lens. This article is aimed to further our knowledge in this area and provide implications for future education and research.

Specifically, this review aims to address the following questions:

1. What are the main theoretical approaches and definitions of language mixing studies used by scholars in heritage language education contexts?

2. How is language mixing pedagogy characterized in heritage language instruction? How have researchers examined its effectiveness?

3. What factors or roles have researchers identified for language mixing outside of formal instruction?

\section{RESEARCH METHDOLOGY}

In this section, the process of data collection and analysis is presented, namely how the primary resources were identified and analyzed. Guided by the research questions, a systematic review was conducted to investigate the role of language mixing activities in heritage language learning in family, community, and school). systematic reviews are:

literature reviews adhere closely to a set of scientific methods that explicitly aim to limit systematic error (bias), mainly by attempting to identify, appraise and synthesize all relevant studies (of whatever design) in order to answer a particular question (or set of questions). (Petticrew \& Roberts, 2012, p. 9)

Petticrew and Roberts state that this kind of review is valuable when there is a need to answer a set of questions and further provide implications for research and practices in a certain area (2012).

\subsection{Data Collection}


In order to identify qualified empirical studies and capture the latest research rends, three main databases were employed: Scopus, Web of Science, and Linguistics and Language Behavior Abstracts (LLBA). For quick detection of qualified papers among hundreds of millions of resources, the combination of two sets of keywords was used on these databases: (1) language mixing keywords including "translangauging", "code-switching", "codemixing", and "language mixing" and (2) heritage language keywords which are "heritage language", "mother tongue', as well as "native language". According to the research questions, the author set the following inclusion criteria: (1) published with full-text on peerreviewed journals for relatively higher quality; (2) written in English due to the richer data in English and the author's personal language repertoire; (3) primary studies centering on heritage language learning with language mixing activities; (4) teachers' pedagogical translangauging efforts are studied in real heritage language education settings, which means the content subject is heritage language per se; (5) the language mixing activities in families and communities are aimed at heritage language development. Since there are not many empirical research articles on this topic, no time limitation is involved for studies.

In line with the above inclusion criteria, sources involving the following criteria were excluded: (1) secondary studies focusing on previous literature; (2) academic publications other than peer-reviewed journal articles, including non-peer-reviewed journal article, books, book chapters, proposals; (3) articles not written in English; (4) pedagogical translanguaging mainly aimed at teaching academic subjects rather than heritage language, such as translangauging teaching activities in a science class; (5) language mixings in families and communities targeting at the development of the dominant language or bilingualism; (6) studies focusing on the linguistic analysis of the language mixings; (7) language mixings in the virtual world.

To identify the appropriate studies, two main rounds of selection were carried out with the inclusion and exclusion criteria. At first, the author searched with the aforementioned keywords on the three databases and found 98 empirical articles with various foci. Second, after reading the abstracts or full texts of these articles, 75 articles were removed. As a result, 23 empirical articles meet the inclusion criteria and were analyzed for this systematic review, including 17 articles in the educational settings (including heritage language classes at daily schools, heritage language weekend schools and after-schools, heritage language workshops, and heritage language tutoring sessions) and 6 articles for family and community. It has to be pointed out that there are only 22 studies involved in this review. Because Vijayakumar, Steinkrauss, and Sun's article (2020) is a close re-examination of the Tamil classes reported by Sun et al. (2020) who investigated 20 teachers' translangauging behaviors in Mandarin, Malay, and Tamil heritage language classes in Singapore. Additionally, the books investigated by Kelly (2020) are used by schools, families, and libraries and they are categorized as language mixing materials in educational settings.

\subsection{Data Analysis}

Thematic analysis and frequency analysis were employed to provide better insights into the characteristics of the pedagogical translangauging and its effects on heritage language development. NVivo 12 was used to organize the primary sources with clarity and efficiency. First, after skimming the selected articles, general codes were generated. Second, based on the general codes in the first step, a list of possible themes for the three research questions was created. Third, the themes and codes were revised after carefully analyzing the related contents in these articles. During this step, the coherence and distinction of the codes were checked. Last, the frequency of each code was examined to report the research trends of language mixing in heritage language settings in terms of ways and its effectiveness. 


\section{RESULTS}

To illustrate the backgrounds of these studies, two tables are provided in this section, respectively created for studies in- and out-of-school settings. The earliest article was published in 2011 by Creese's team indicating that heritage language learning through a language mixing lens is a newly established area. Among the 23 articles, 4 were published in 2019, and 12 were released in 2020. In the future, we will witness an increasing number of studies with various foci in this area. Regarding the countries of the study, English-dominant countries, especially the US with 11 articles (e.g., Menken \& Avni, 2017; Rowe, 2019), account for the biggest slice of the cake. Other regions include Singapore (Sun et al., 2020), Zimbabwe (Mazuruse \& Mberi, 2012), Sweden (Dávila \& Bunar, 2020), Italy (Ghimenton, 2015) and Bolivia (Hornberger \& Swinehart, 2015), suggesting the strong need to further our knowledge in contexts where English is not the official language or widely spoken. This may also be attributed to the inclusion criterion of English-written articles for this review. As for the target heritage language, Spanish is the most reported language, followed by Korean. Immigrant languages are dominant in current research such as Chinese varieties in the States (Wu \& Leung, 2020) and Tamil in Australia (Perera, 2020). However, only three works deal with the revitalization of indigenous languages including Higgins's (2019), Hornberger and Swinehart's (2012, and Mazuruse and Mberi's (2012). In addition, there is one article presenting the engagement of an Italian family in the maintenance of Veneto dialect (Ghimenton, 2015).

Table 1

Background Information of the Empirical Studies in Educational Settings

\begin{tabular}{|c|c|c|c|c|}
\hline No. & Article & $\begin{array}{l}\text { Heritage } \\
\text { Language }\end{array}$ & Country & Educational Settings \\
\hline 1 & Barbour \& Quinn (2020) & $\begin{array}{l}\text { Multiple } \\
\text { languages }\end{array}$ & UK & $\begin{array}{l}\text { A creative writing workshop for } \\
\text { third graders }\end{array}$ \\
\hline 2 & Belpoliti\& Perez (2019) & Spanish & US & $\begin{array}{l}\text { An advanced Spanish class with } \\
\text { professional fairs for the Health } \\
\text { Professionals course at a } \\
\text { university }\end{array}$ \\
\hline 3 & Bonomi (2020) & Spanish & Italy & $\begin{array}{l}\text { A weekly extracurricular } \\
\text { workshop in a secondary school }\end{array}$ \\
\hline 4 & Creese et al. (2011) & $\begin{array}{l}\text { Gujarati, } \\
\text { Cantonese, } \\
\text { Bengali, } \\
\text { Turkish }\end{array}$ & UK & $\begin{array}{l}\text { Four community complementary } \\
\text { schools }\end{array}$ \\
\hline 5 & Dávila\&Bunar (2020) & $\begin{array}{l}\text { Multiple } \\
\text { languages }\end{array}$ & Sweden & $\begin{array}{l}\text { In and out of Swedish-medium } \\
\text { classroom in urban Swedish } \\
\text { schools }\end{array}$ \\
\hline 6 & $\begin{array}{l}\text { Hornberger \&Swinehart } \\
(2012)\end{array}$ & $\begin{array}{l}\text { Aymara, } \\
\text { Quechua }\end{array}$ & Bolivia & $\begin{array}{l}\text { A master program for teaching } \\
\text { Aymara and Quechua }\end{array}$ \\
\hline 7 & Kelly (2020) & Spanish & US & $\begin{array}{l}\text { Language-mixing books used by } \\
\text { teachers, parents, and library }\end{array}$ \\
\hline 8 & Kim \& Park (2020) & Korean & US & $\begin{array}{l}\text { A one-to-one poetry writing } \\
\text { workshop }\end{array}$ \\
\hline 9 & Lee \& García (2020) & Korean & US & $\begin{array}{l}\text { A Korean heritage language } \\
\text { classroom }\end{array}$ \\
\hline 10 & Mazuruse\&Mberi (2012) & Shona & Zimbabwe & $\begin{array}{l}\text { Tertiary-level Shona language } \\
\text { classes }\end{array}$ \\
\hline 11 & Menken \& Avni (2017) & Hebrew & US & $\begin{array}{l}\text { A dual-language bilingual } \\
\text { program in a New York City }\end{array}$ \\
\hline
\end{tabular}




\begin{tabular}{|c|c|c|c|c|}
\hline 12 & Perera (2020) & Tamil & Australia & $\begin{array}{l}\text { Public Middle school } \\
\text { A Tamil Hindu temple school }\end{array}$ \\
\hline 13 & Reznicek-Parrado (2020) & Spanish & US & $\begin{array}{l}\text { Tutoring sessions of a Spanish-as- } \\
\text { a-heritage-language program at a } \\
\text { university }\end{array}$ \\
\hline 14 & Rowe (2019) & $\begin{array}{l}\text { Multiple } \\
\text { Languages }\end{array}$ & US & A public elementary school \\
\hline 15 & Sun et al. (2020) & $\begin{array}{l}\text { Mandarin, } \\
\text { Malay, Tamil }\end{array}$ & Singapore & $\begin{array}{l}\text { Heritage language classes at } \\
\text { kindergartens }\end{array}$ \\
\hline 16 & $\begin{array}{l}\text { Vijayakumar et al. } \\
(2020)\end{array}$ & Tamil & Singapore & $\begin{array}{l}\text { A Tamil language class at a } \\
\text { kindergarten }\end{array}$ \\
\hline 17 & Wu \& Leung (2020) & $\begin{array}{l}\text { Chinese } \\
\text { language } \\
\text { varieties } \\
\text { (Mandarin, } \\
\text { Fujianese, } \\
\text { Cantonese, } \\
\text { Hakka, } \\
\text { Teochew) }\end{array}$ & US & $\begin{array}{l}\text { A heritage language class at a K- } 8 \\
\text { charter school }\end{array}$ \\
\hline
\end{tabular}

Note: Kelly's project (2020) was applied to schools, families, and communities. For convenience, it is listed in Table 1.

Table 2

Background Information of the Empirical Studies in the Out-of-School Settings

\begin{tabular}{|c|c|c|c|c|}
\hline No. & Article & $\begin{array}{l}\text { Heritage } \\
\text { Language }\end{array}$ & Country & Out-of-School Settings \\
\hline 1 & Canagarajah (2012) & Tamil & $\begin{array}{l}\text { UK, US, } \\
\text { Canada }\end{array}$ & Tamil Diasporas \\
\hline 2 & Ghimenton (2015) & Veneto Dialect & Italy & One Veneto-Italian Family \\
\hline 3 & Higgins (2019) & Hawaiian & US & Hawaiian-American families \\
\hline 4 & Kwon (2019) & Korean & US & $\begin{array}{l}\text { Temporal visits of three Korean- } \\
\text { American families to museums in } \\
\text { Korea }\end{array}$ \\
\hline 5 & Song (2016) & Korean & US & Korean-American Families \\
\hline 6 & Wilson (2020) & French & UK & French-English Families \\
\hline
\end{tabular}

\subsection{Theoretical Approaches and Definitions of Language Mixing}

Language mixing is a broad and neutral term defining the processes and the products of using more than one language for meaning-making. Under this umbrella, there are diverse terms (e.g., code-switching, code-meshing, translingual, translanguaging) employed by scholars since they have not reached a consensus on the nature of language. Some empirical works lack clear overarching language mixing terms as they do not touch upon the nature of language in-depth. InMazuruse\&Mberi's project at Great Zimbabwe University (2012), the Shona teachers use "code-switching", "code-mixing" and "borrowing" by resorting to English (p. 2026). Ghimenton'sresearch (2013) involves grandparents' "mixed utterances" of Veneto and Italian (p. 133). Although there has been a shift in the perceptions of language, from separate and settled to fluid and flexible, a few researchers use some language mixing terms interchangeably in their articles as these terms are not divergent on the surface level. For example, the classroom translation activities are described as "translanguaging" or "translingual" in Rowe's research (2019).

Thirteen articles adopt "translanguaging" as the guiding term of language mixing. It came as no surprise since they were published between 2016 to 2020 with translanguaging 
burgeoning in language education academia. However, translanguaging has various entailments among these articles. Kelly's article (2020) used a general definition from Lews, Jones and Baker's work (2012) as the "spontaneous, everyday way of making meaning, shaping experiences, and communication by bilinguals" (p. 641). In Barbour and Quinn's report (2020), translanguaging does not only involve code-switching "between languages in alternate clauses or sentences" and code-mixing "between languages within sentences, clauses or even words" (p. 9), but also refer to the fluid cognitive process of language constructing and communicating ( $\mathrm{Li}, 2008$, as cited by Barbour \& Quinn, 2020). The most frequent definitions of translanguaging applied to these empirical studies came from García's (2009) and Otheguy et al.'s (2015) works, emphasizing the full linguistic repertoires of speakers and deconstructing named languages. In another word, most of the primary sources approach language mixing as a resource, encouraging students and their families to leverage full linguistic repertoires in communication while blurring the boundaries and hierarchies of languages. On the basis of the resource-oriented language mixing theory, researchers designed their studies with theoretical frameworks such as flexible bilingualism (Creese et al. 2011; Hornberger \&Swinehart, 2012), flexible language practices (Perera, 2020), translanguaging pedagogy (Barbour \& Quinn, 2020), translanguaging and academic literacy (Reznicek-Parrado, 2020) and so forth.

On the other hand, some scholars who are aware of the language boundaries approach language mixing as an instructional strategy and adopt "code-switching" as their theoretical framework. Sun and her team (2020) investigated the roles of teachers' code-switching in students' development of heritage language and cognition, defining code-switching as "an alternation between languages, either within (intra-sentential switching) or between (intersentential switching) sentences or utterances" (p. 311). Strategy-orientated language mixing is also reflected in and reflective of Mazuruse and Mberi's study (2012). They regard codeswitching as an instrumental teaching strategy to facilitate students' motivation, comprehension, expression, communication, and fault correction (Ogutu, 2006, as cited by Mazuruse\&Mberi, 2012).

\subsection{Language Mixings in Educational Settings}

\subsubsection{Language Mixings as a Pedagogy}

The educational contexts reported by the empirical data vary from early childhood (e.g., Sun et al., 2020) to tertiary level (e.g., Mazuruse\&Mberi, 2012). For answering the second research question, "pedagogical translangauging" and "spontaneous translangauging" from Cenoz and Gorter's work (2017) are employed. During the detailed data analysis process, four themes were generated for pedagogical translangauging: translangauging speech, translangauging materials, creative writing activities, cross-linguistic comparisons.

\section{Translanguaging Speech}

Nearly all the heritage language educators purposefully mix the languages in class or encourage their students to do so for scaffolding comprehension and making students more engaged. The educators mix heritage languages and dominant languages with different frequencies. For example, in Dávila and Bunar's study (2020) in Sweden, the multilingual teaching assistances tend to keep a balance between the use of students' home language and Swedish since they are responsible for helping the immigrant students maintain the home languages as well as survive in the new environment. In Perera's research (2020), the Tamil teacher predominantly teaches in Tamil and uses English words sometimes for emphasis. Translanguaging speech is indispensable in Mazuruse \& Mberi's research setting (2012) primarily because of the lack of the equivalents in Shona of academic English terms such as "aspiration" and "vocal tract" (p. 2027). It is reported as an effective strategy for dealing with unfamiliar content to students (Mazuruse\&Mberi, 2012). This may be widespread in 
indigenous language education due to the limitation of modern and technical vocabulary. Besides, translangauging speech happens at various levels. For example, in Kim and Park's poem writing workshop (2020), the teacher asked the students with intra-sentential language mixing: "Do you want to put '이제는현실이라 (Now, it is a reality)' or just '현실이라 (It is a reality)'?" (p. 298). Then the teacher mixes the two languages in the inter-sentential level: "네 (Yes). You need the first two chunks here . . 아까말씀하실때, 여기공항에서만났을때, 이거를더 vivid 하게설명해주셨던것같은데. 문이이렇게열리면서, 울었다고하셨잖아요. (When you talked about it, I think you explained this more vividly. You said that you cried when the landing gate opened)" (p. 298).

Translanguaging Materials

A few studies identify the application of translangauging materials (e.g., Menken \& Avni, 2017; Hornberger \& Swinehart, 2012). It is assumed that the materials provided for students are different according to their language proficiency and age. For example, in Menken and Avni's study (2017), for heritage language learners of Hebrew in early ages, a 6th-grade teacher created PowerPoint slides using English, Hebrew and Arabic, and a Hebrew-English glossary was provided for 7th-graders. In Hornberger and Swinehart's research for advanced language learners in a master program (2012), the teacher divided the students into groups and asked them to analyze an interview excerpt with a fluid mixture of Quechua and Spanish.

\section{Creative Writing}

Creative writing activity for poetry or books is documented in three articles (Barbour \& Quinn, 2020; Kim \& Park, 2020; Rowe, 2019). In the multilingual class observed by Barbour and Quinn (2020), students are encouraged to write poems using English and other languages outside school. Kim and Park's study (2020) showcases the processes and products of a Korean heritage learner's compositions of Sijo poetry. For students with multiple linguistic backgrounds in Rowe's class (2019), eBooks composed on iPads integrate their written texts and audio recordings of reading the texts. In addition, peer translation is presented in Rowe's (2019) and Barbour and Quinn's research (2020) as students enthusiastically invited their classmates to translate the texts into different languages.

\section{Cross-Linguistic Comparisions}

There are four studies involving cross-linguistic comparisons (Bonomi, 2020, Dávila \& Bunar, 2020; Lee \& García, 2020; Wu \& Leung, 2020). According to them, this practice is usually encouraged for languages with structural closeness. The first study (Bonomi, 2020) in Italy presents that the cognate charts were used for Spanish heritage speakers to reflect on the similarities and differences between Spanish and Italian, the two Romance languages. In Dávila and Bunar's study (2020), the teaching assistant from Palestine talked about the differences between Arabic varieties to the student from Iraq. Wu and Leung's article (2020) depicts how a Mandarin teacher invited her Chinese heritage students to compare Mandarin, the assigned heritage language, with their real home languages such as Cantonese and Fujianese. For instance, the teacher explained that in Mandarin, the bed is called “床” whereas in Teochew, her home language, the bed (床) is called “bed for sleeping (眠床)” (p. 10). Later, students from Fujian expressed that Fujianese had similar ways of saying as they also called the bed a sleeping bed. This evoked hot discussions in class based on the comparisons across Mandarin, Fujianese, and Cantonese. Such cross-linguistic analyses facilitate students' cross-cultural competences, as shown by Benattabou (2020).

Spontaneous Translanguaging 
Spontaneous translangauging refers to the habitual translangauging activities without consciousness. Although it may happen in every study, it is only explicitly discussed in two papers (Sun et al., 2020; Vijayakumar et al., 2020). According to the collected questionnaire, the researchers (Sun et al., 2020) point out that, in fact, the heritage language teachers deliver spontaneous translangauging speech more frequently with students than the translangauging speech with purpose.

\subsubsection{Impacts of Language Mixings}

This paper presents the impacts of language mixing pedagogy with three themes: the language, the self, and the society.

\section{The Language}

Language development is the second most discussed impact of pedagogical translanguaging in the existing studies. Students' flexible language uses and improving metalinguistic awareness are presented as the most remarkable affordances in terms of language development. On one hand, performing as models, teachers' translanguaging expressions in oral and written forms encourage students to engage in translangauging activities and as such, improved their flexible language uses (e.g., Creese \& Blackledge, 2011; Menken, \& Avni, 2017; Sun et al., 2020). For example, as shown in Menken and Avini's paper (2017), guided by the teachers, Hebrew students frequently mix languages while speaking in class. On the other hand, students' improvement of meta-linguistic awareness is discussed by many studies, especially those with cross-linguistic comparisons (Bonomi, 2019; Dávila \& Bunar, 2020; Wu \& Leung, 2020). Besides, the translanguaging pedagogy gives spaces for different language varieties under the big language umbrellas (Bonomi, 2020; Wu \& Leung, 2020). Many Chinese students in Wu \& Leung's work (2020) are from families speaking minority Chinese language varieties such as Cantonese and Fujianese but they are enrolled in the Mandarin heritage language classrooms. With the teacher's translanguaging efforts, these minority Chinese languages are discussed and embraced by students. In Bonomi's work (2020), all varieties of Spanish are introduced to Hispanic students.

However, only a few studies directly report the development of heritage language thanks to pedagogical translanguaging (Belpoliti\& Pérez, 2019; Sun et al., 2020). Some students in recognize their improved performance as Spanish-speaking health professionals (Belpoliti\& Pérez, 2019). Sun and her (2020) team tried to find out whether teachers' codeswitching behaviors relate to children's development in heritage language vocabulary, but it turned out that neither intra-sentential nor inter-sentential code-switching showed a significantly positive relationship with heritage language vocabulary development.

\section{The Self}

Heritage learners' self-construction is the most frequently documented impact from the empirical data. Due to the limited representation of their home languages and cultures at the majority schools, heritage language speaking students often present more learning and behavior problems which leads to higher dropout rates (Bonomi, 2020). The low engagement of minority students is presented in Wu and Leung's study (2020). In their study, Mandarin is assigned as their Chinese home language despite their real Chinese heritage language variety. Feeling that they are not on the same page with their Mandarin-speaking peers, these students hardly engage in the class and become less invisible and inaudible. After the teacher's introduction of multiple Chinese language varieties in class and the hot discussion on these varieties in class, the students feel more confident speaking their heritage language and sometimes voluntarily teach the language varieties to their teacher and peers. However, sometimes students may reject their role as language brokers. In Rowe's class (2019), a boy 
who is the only speaker of his heritage language class refuses to translate for his peers as he feels unprepared and unsupported.

\section{The Society}

Language mixing makes contributions to students' connection to their ethnic communities (Belpoliti\& Pérez, 2019; Hornberger \&Swinehart, 2012; Reznicek-Parrado, 2020) and encourages them to think critically regarding linguistical inequality issues (Wu \& Leung, 2020). Take Belpoliti and Pérez's study as an example (2019) through translanguaging service learning, the Spanish-speaking in health professions have acquired a strong sense of community and gained deep insights into the health needs of Hispanic immigrants, paving the way for their better service for local ethnic community. In ReznicekParrado's report (2020), not only does the translanguaging communication led by the tutors contribute to students' Spanish acquisition, but also strengthen their sense of belongings to the Spanish-Speaking student community since these conversations provide emotional support for them.

In addition to the affordances benefited above, some studies also report that language mixing pedagogy facilitates peer collaboration and learning. In creative writing activities, students enthusiastically invite their classmates to translate the texts into different home languages (Rowe, 2019; Barbour \& Quinn, 2020). In Wu and Leung's study (2020), students' discussion about similarities and differences among Mandarin, Cantonese, and Fujianese contributes to their learning of various Chinese language varieties from each other.

\subsection{Language Mixings in Family and Community}

Outside community language schools, there is no empirical data on how communities make language mixing efforts on heritage language maintenance except the speech and song contests held by Tamil diasporas mentioned by Canagarajah (2012). In contrast, 6 articles report the role of language mixing in family heritage language learning even though they are not as many as studies in educational settings (Canagarajah, 2012; Ghimenton, 2015; Higgins, 2019; Kwon, 2019; Song, 2016; Wilson, 2020). As a microcosm, family plays an essential role in minority language maintenance and revitalization (Fishman, 1970). In this section, the language mixing strategies adopted by caretakers and their impacts on children's heritage language development are discussed.

Resonating with pedagogical translanguaging, the most widely applied language mixing activities for parents is language mixing speech which appears in all the studies. Beyond daily conversations, this activity sometimes happens in engaging sites or moments. A few Korean-American parents used English and Korean with their children during their temporal visits to the museums in Korea, as documented by Kwon (2019). The museums opened the floor for parents to share their family stories in the mixed language with multimodal exhibitions. For instance, hearing the stories of their family members in the Korean War or arranged marriage, the children showed strong interest in continuing the conversations. This activity enlarges children's Korean language repertoire and strengthens family rapport across generations.

Translation is also reported as an effective way for heritage language learning, which is emphasized by Song (2016). There are two types of translation activities presented in her article. First, parents usually ask questions like "What is it in Korean?" and "What is it in English?" (Song, p. 96) after they offer translations for new words or expressions to check their children's comprehension. Second, joint translation is also adopted by the parents. When the children translate what they have read or watched to their parents from English to Korean, the parents help them to express their ideas in Korean and later asked them to confirm (Song, 2016). 
Besides, trans-enunciating is employed by parents in Song's (2016) and Canagarajah's (2012) studies. For instance, a mother helped her sons prepare for the local diaspora's Tamil speech context by enunciating the whole speech in Tamil and inviting her sons to write it down in English (Canagarajah, 2012). Later, she explained the general meaning and the context of the speech for her sons. Mixed perceptions arise toward this type of language mixing activity. As presented by Canagarajah (2012). while some people believe that it helps the children to learn the heritage culture and traditional values, others negatively regard it as just imitation without authentic reflection.

\section{DISCUSSION AND CONCLUSION}

Earlier in this paper, the author shows two main theoretical frameworks of language mixing employed by the empirical data: (a) resource-oriented language mixing viewing personal and societal linguistic repertoires as integrated, such as "translanguaging"; (b) function-oriented language mixing based on the boundaries between named languages, such as "code-switching". This section discusses the pros and cons of the two theoretical orientations in the heritage language education arena.

With no doubt, the resource-oriented language mixing theory has some advantages. First, it valorizes societal diversity and brings everyone's linguistic and cultural knowledge into language education. This facilitates the family engagement in language learning classrooms and endows students with the roles of language broker, especially in creative activities such as the composition of storybooks presented by Rowe (2019). Second, as a glottopolitical tool, language mixing "encourages linguistic activism and a culture of resistance, legitimizing all repertoires and discourses in response to dominant norms and ideologies that not always fit within real language practices of minority groups" (Bonomi, 2020 , p. 50). In a debate of $\mathrm{Wu}$ and Leung's class (2020) about the relationship between different Chinese language varieties and job markets, students expressed their images of the typical jobs connected to Mandarin, Fujianese, and Cantonese and discussed their ideas of high and low jobs. This provides a valuable opportunity for students to question language hegemony and social injustice.

However, this theoretical approach has some limitations. On the one hand, it may be not effective in language classrooms reliant on standard tests. Regardless of the boundaries between languages, teachers would find it hard to provide answers and standards for the assessments. Second, without emphasis on the differences between languages, students are easily reliant on the majority language due to its high social status and the large amount of input. As a result, the minority language may become "a kitchen language" only spoken at home for simple topics (Zhang, 2012, p. 218). Considering these limitations, language mixing as strategies based on discrete languages is beneficial to some degree. Not only does it make language assessment more convenient, but also improve learners' metalinguistic awareness of both languages by cross-linguistic comparisons (e.g., Bonomi, 2019; Dávila \& Bunar, 2020). Hence, Spivak's strategic essentialism (1993) for research through a language mixing lens is recommended. Even though language repertoire is hybrid and fluid, speakers strategically switch to appropriate linguistic resources for different contexts and purposes, showcasing different identities (Canagarajah, 2012).

In summary, this systematic review identifies the language mixing efforts and their impacts on heritage language learning in households, communities, and classrooms. It is hoped that this paper could provide a general introduction to the relevant research status quo and implications for future research and education. As the result section suggests, language mixing practices lead to the improvement of the heritage speakers' linguistic capacities and identity constructions, as well as the betterment of our society in various aspects. According to the review, more research in family and community is strongly warranted, especially in the community contexts. Future research could investigate heritage language education through 
the community translanguaging lens (Kim, Dorner, and Song, 2021) to show how community, family, and school create synergy in service of the children's language development. However, the studies in this review are limited as only English-written peerreviewed journal articles are included. Further literature reviews could cover multiple types of sources including, in part, book chapters and conference proceedings, published in different languages. Moreover, other aspects of this field such as heritage language learners' language mixings in the virtual world are worthy of exploration.

Conflict of interests: The author declares no conflict of interest.

REFERENCES (* is used for the reviewed empirical articles)

Backus, A. (2005). Codeswitching and language change: One thing leads to another? International Journal of Bilingualism, 9(3-4), 307-340. https://doi.org/10.1177/13670069050090030101

*Barbour, C., \& Lickorish Quinn, K. (2020). Los pájaros are feliz and are dreaming about gwiazdy: Facilitating translingual creative writing in the primary classroom. English in Education, 54(1), 6-26. https://doi.org/10.1080/04250494.2019.1703553

*Belpoliti, F., \& Pérez, M. E. (2019). Service learning in Spanish for the health Professoins: Heritage language learners' competence in action. Foreign Language Annals, 52(3), 529-550. https://doi.org/10.1111/flan.12413

Benattabou, D. (2020). Developing intercultural competence among Moroccan EFL students: Focusing on their cross-cultural awareness. International Journal of Language and Literacy Studies, 2(3), 43-56. https://doi.org/10.36892/ijlls.v2i3.339

Beaudrie, S. M. (2011). Spanish heritage Language programs: A snapshot of current programs in the Southwestern United States. Foreign Language Annals, 44(2), 321337. https://doi.org/10.1111/j.1944-9720.2011.01137.x

Blackledge, A., \& Creese, A. (2010). Multilingualism. Continuum.

*Bonomi, M. (2020). Mi(s) Lengua(s): Educational paths for Hispanic students within Italian school. Journal of Multilingual and Multicultural Development,41(1), 45-58. https://doi.org/10.1080/01434632.2019.1621875

*Canagarajah, A. S. (2012). Migrant ethnic identities, mobile language resources: Identification practices of Sri Lankan Tamil youth. Applied Linguistics Review, 3(2), 251-272. https://doi.org/10.1515/applirev-2012-0012

Cenoz, J. (2017). Translanguaing in school context. International perspectives: An introduction. Journal of language, Identity and Education, 16, 193-198. https://doi.org/10.1515/applirev-2012-0012

Cenoz, J. (2017). Translanguaing in school context. International perspectives: An introduction. Journal of language, Identity and Education, 16, 193-198. https://doi.org/10.1080/15348458.2017.1327816

Cenoz, J., \& Gorter, D. (2017). Sustaining translanguaging and minority languages: Threat or opportunity? Journal of Multilingual and Multicultural Development, 38, 901-912. https://doi.org/10.1080/01434632.2017.1284855

Childs, M. (2016). Reflecting on translanguaging in multilingual classrooms: Harnessing the power of poetry and photography. Educational Research for Social Change, 5(1), 2240. https://doi.org/10.17159/2221-4070/2016/v5i1a2

Cho, G. (2000). The role of heritage language in social interaction and relationships: Reflections from language minority groups. Bilingual Research Journal, 24(4), 369384. https://doi.org/10.1080/15235882.2000.10162773 
*Creese, A., \& Blackledge, A. (2011). Separate and flexible bilingualism in complementary schools: Multiple language practices in interrelationship. Journal of Pragmatics,43(5), 1196-1208. doi: 10.1016/j.pragma.2010.10.006

Creese, A., \& Blackledge, A. (2015). Translanguaging and identity in educational settings. Annual Review of Applied Linguistics, 35, 20-35. https://doi.org/10.1017/s0267190514000233

*Dávila, L.T., \&Bunar, N. (2020). Translanguaging through an advocacy lens: The roles of multilingual classroom assistants in Sweden. European Journal of Applied Linguistics, 8(1), 107-126. https://doi.org/10.1515/eujal-2019-0012

Fishman, J. A. (1964). Language maintenance and language shift as a field of inquiry. Linguistics, 2(9), 32-70. https://doi.org/ 10.1515/ling.1964.2.9.32

Fishman, J. A. (1970). Sociolinguistics: A brief introduction. Newbury House.

Fishman, J. A. (2001). 300-plus years of heritage language education in the United States. In J. K. Peyton, D. A. Ranard, \& S. McGinnis (Eds.), Heritage language in America: Preserving a national resource (pp. 81-98). Center for Applied Lingusitics \& Delta Systems.

García, O. (2009). Bilingual education in the twenty-first century: A global perspective. Wiley-Blackwell.

García, O., \& Kano, N. (2014) "Translanguaging as Process and Pedagogy: Developing the English Writing of Japanese Students in the US." In J. Conteh \& G. Meier (Eds.), The Multilingual Turn in Languages Education: Opportunities and Challenges (pp. 258277). Lavenham Press Ltd.

García, O., \& Li, W. (2014). Translanguaging: Language, bilingualism and education. Palgrave MacMillan.

*Ghimenton, A. (2013). Reading between the code choices: Discrepancies between expressions of language attitudes and usage in a contact situation. International Journal of Bilingualism, 19(1), 115-136. https://doi.org/10.1177/1367006913509900

Gort, M., \& Sembiante, S. F. (2015). Navigating hybridized language learning spaces through translanguaging pedagogy: Dual language preschool teachers' languaging practices in support of emergent bilingual children's performance of academic discourse. International Multilingual Research Journal, 9(1), 7-25. https://doi.org/10.1080/19313152.2014.981775

Gutiérrez, K., Baquedano-López, P., \& Alvarez, H. (2001). Literacy as hybridity. In M, de la Luz Reyes, \& J. J. Halcón (Eds.), The best for our children (pp. 122-141). Teachers College Press.

Gutiérrez, K. D., Baquedano-López, P., \& Tejeda, C. (1999). Rethinking diversity: Hybridity and hybrid language practices in the third space. Mind, Culture, and Activity, 6(4), 286303. https://doi.org/10.1080/10749039909524733

He, A. W. (2010). The heart of heritage: Sociocultual dimensions of heritage language learning. Annual Review of Applied Linguistics, 30, 66-82. https://doi.org/10.1017/S0267190510000073

*Higgins, C. (2019). The dynamics of Hawaiian speakerhood in the family. International Journal of the Sociology of Language, 2019(255), 45-72. https://doi.org/10.1515/ijsl2018-2003

*Hornberger, N. H., \&Swinehart, K. F. (2012). Bilingual intercultural education and Andean hip hop: Transnational sites for indigenous language and identity. Language in Society, 41(4), 499-525. https://doi.org/10.1017/s0047404512000486

*Kelly, L. B. (2020). An analysis of Spanish use in award-winning children's picturebooks. Journal of Multilingual and Multicultural Development, 1-14. https://doi.org/10.1080/01434632.2020.1715987 
*Kim, K. M., \& Park, G. (2020). "It Is More Expressive for Me": A Translingual Approach to Meaningful Literacy Instruction Through Sijo Poetry. TESOL Quarterly,54(2), 281309. https://doi.org/10.1002/tesq.545

Kondo-Brown, K. (2003). Heritage language instruction for post-secondary students from Immigrant backgrounds. Heritage Language Journal, 1(1), 1-25. https://doi.org/10.46538/hlj.1.1.1

*Kwon, J. (2019). Parent-Child translanguaging among transnational immigrant families in museums. International Journal of Bilingual Education and Bilingualism, 1-16. https://doi.org/10.1080/13670050.2019.1689918

Li, G. (2008). Culturally contested literacies: America's "rainbow underclass" and urban schools. Routledge.

Leeman, J. (2015). Heritage language education and identity in the United States. Annual Review of Applied Linguistics, $100-119$. https://doi.org/10.1017/S0267190514000245

*Lee, C., \& García, G. E. (2020). Unpacking the oral translanguaging practices of KoreanAmerican first graders. Bilingual Research Journal, 43(1), 32-49. https://doi.org/10.1080/15235882.2019.1703844

Lewis, G., Jones, B., \& Baker, C. (2012). Translanguaging: Origins and Development From School to Street and Beyond. Educational Research and Evaluation: An International Journal on Theory and Practice, 18 (7), 641-654. https://doi.org/10.1080/13803611.2012.718488.

Li, G. (2006). Biliteracy and trilingual practices in the home context: Case studies of Chinese-Canadian children. Journal of Early Childhood Literacy, 6(3), 359-385. https://doi.org/10.1177/1468798406069797

Machado, E., \& Hartman, P. (2019). Translingual writing in a linguistically Diverse primary classroom. Journal of Literacy Research, 51(4), 480-503. https://doi.org/10.1177/1086296x19877462

*Mazuruse, M., \&Mberi, E. N. (2012). Language Raising, Empowerment and Development: The Case of Shona Language at Great Zimbabwe University. Theory and Practice in Language Studies, 2(10), 2024-2034. https://doi.org/10.4304/tpls.2.10.2024-2034

*Menken, K., \& Avni, S. (2017). Challenging Linguistic Purism in Dual Language Bilingual Education: A Case Study of Hebrew in a New York City Public Middle School. Annual Review of Applied Linguistics, 37, 185-202. https://doi.org/10.1017/s0267190517000149

$\mathrm{Ng}$, S. H., \& He, A. (2004). Code-switching in trigenerational family conversations among Chinese immigrants in New Zealand. Journal of Language and Social Psychology, 23(1), 28-48. https://doi.org/10.1177/0261927x03260807

Oriyama, K. (2010). Heritage language maintenance and Japanese identity formation: What role can schooling and ethnic community contact play? Heritage Language Journal, 7(2), 237-272. https://doi.org/10.46538/hlj.7.2.5

Otheguy, R., García, O., \& Reid, W. (2015). Clarifying translanguaging and deconstructing named languages: A perspective from linguistics. Applied Linguistics Review, 6(3), 281-307. doi:10.1515/applirev-2015-0014

Petticrew, M., \& Roberts, H. (2012). Systematic reviews in the social sciences: A practical guide. Blackwell.

*Perera, N. (2020). Talking Saivism in a Tamil migrant faith classroom. International Journal of Multilingualism, 1-17. https://doi.org/10.1080/14790718.2020.1712406

Poplack, S, Zentz, L., \& Dion, N. (2011). Phrase-final prepositions in Quebec French: An empirical study of contact, code-switching and resistance to convergence. Bilingualism: Language and Cognition, 15(2), 203-225. https://doi.org/10.1017/s1366728911000204 
*Reznicek-Parrado, L. M. (2020). Peer-to-peer translanguaging academic spaces for belonging: the case of Spanish as a heritage language. International Journal of Bilingual Education and Bilingualism, 1-15. https://doi.org/10.1080/13670050.2020.1799320

*Rowe, L. W. (2019). Emergent bilingual students' translation practices during eBook composing. Bilingual Research Journal,42(3), 324-342. https://doi.org/10.1080/15235882.2019.1632756

Sayer, P. (2008). Demystifying language mixing: Spanglish in school. Journal of Latinos and Education, 7(2), 94-112. https://doi.org/10.1080/15348430701827030

*Song, K. (2015). "Okay, I will say in Korean and then in American": Translanguaging practices in bilingual homes. Journal of Early Childhood Literacy, 16(1), 84-106. https://doi.org/10.1177/1468798414566705

Spivak, G. C. (1993). Outside in the teaching machine. Routledge.

Stewart, M. A., \& Hansen-Thomas, H. (2016). Sanctioning a space for translanguaging in the secondary English classroom: A case of a transnational youth. Research in the Teaching of English, 50, 450-472.

*Sun, H., Yussof, N., Vijayakumar, P., Lai, G., O’Brien, B. A., \& Ong, Q. H. (2020). Teacher's code-switching and bilingual children's heritage language learning and cognitive switching flexibility. Journal of Child Language, 47(2), 309-336. https://doi.org/10.1017/s030500091900059x

Tse, L. (2001). Heritage language literacy: A study of US biliterates. Language, Culture and Curriculum, 14(3), 256-268. https://doi.org/10.1080/07908310108666627

Valdés, G. (2005). Bilingualism, heritage language learners, and SLA research: Opportunities lost or seized? The Modern Language Journal, 89, 410-426. https://doi.org/10.1111/j.1540-4781.2005.00314.x

Valdés, G. (1997). The teaching of Spanish to bilingual Spanish-speaking students: Outstanding issues and unanswered questions. In M. C. Colombi \& F. Alarcon (Eds.), La enseñanza del Español a Hhanohablantes: Praxis y teoría (pp. 8-44). Houghton Mifflin.

*Vijayakumar, P., Steinkrauss, R., \& Sun, H. (2020). Entering into the weak version of translanguaging: Teachers' English use in children's Tamil language classes in Singapore. Journal of Multilingual and Multicultural Development, 1-18. https://doi.org/10.1080/01434632.2020.1808003

*Wilson, S. (2020). To mix or not to mix: Parental attitudes towards translanguaging and language management choices. International Journal of Bilingualism, 25(1), 58-76. https://doi.org/10.1177/1367006920909902

*Wu, M., \& Leung, G. (2020). 'It's not my Chinese': A teacher and her students disrupting and dismantling conventional notions of 'Chinese' through translanguaging in a heritage language classroom. International Journal of Bilingual Education and Bilingualism, 1-14. https://doi.org/10.1080/13670050.2020.1804524

Zhang, D. (2012). Co-ethnic network, social class, and heritage language maintenance among Chinese immigrant families. Journal of Language, Identity \& Education, 11(3), 200223. https://doi.org/10.1080/15348458.2012.686408

\section{$\underline{A U T H O R^{\prime}}$ S BIO}

Yizhe Jiang is a PhD Candidate in Foreign, Second, and Multilingual Language Education at The Department of Teaching and Learning, The Ohio State University. Her research interests involve bilingual education, heritage language maintenance, and technology for language teaching and learning. 